\title{
Deregulation of Growth Factor, Circadian Clock, and Cell Cycle Signaling in Regenerating Hepatocyte RXR $\alpha$-Deficient Mouse Livers
}

Xiaoxia Yang, Minglei Guo, and Yu-Jui Yvonne Wan

From the Department of Pharmacology, Toxicology, and Therapeutics, The University of Kansas Medical Center, Kansas City, Kansas

Activation of the nuclear receptors constitutive androstane receptor, pregnane $\mathrm{X}$ receptor, and peroxisome proliferator-activated receptor $\alpha$ results in hepatomegaly, and these nuclear receptors are implicated in the regulation of liver regeneration. Retinoid $\mathrm{X}$ receptor (RXR) $\alpha$ is an essential partner of these nuclear receptors. Therefore, we studied the role of hepatocyte RXR $\alpha$ in liver regeneration using partial hepatectomy model. The results showed that hepatocyte $\operatorname{RXR} \alpha$ deficiency caused an approximately 20-hour delay in hepatocyte proliferation after partial hepatectomy. Several pathways, including growth factors and the circadian cell cycle, were impaired due to hepatocyte RXR $\alpha$ deficiency. In addition, the expression patterns of hepatocyte growth factor, fibroblast growth factor 2, platelet-derived growth factor, and transforming growth factor $\alpha$ were altered due to lack of RXR $\alpha$. Furthermore, the peroxisome proliferatoractivated receptor $\alpha /$ brain and muscle Arnt-like protein 1/Rev-erb $\alpha / \mathbf{P 2 1}$ pathway was compromised, and Cry1/Cry2 and Wee1/Per1 expression was deregulated in regenerating RXR $\alpha$-null livers. Accordingly, the expression and regulation of cyclin D1/Cyclindependent Kinase (Cdk)4, cyclin E1/Cdk2, cyclin A2/ Cdk2, and cyclin B1/Cdk1 after partial hepatectomy were altered in regenerating $\operatorname{RXR} \alpha$-null livers. Hepatocyte RXR $\alpha$ deficiency also affected the basal, as well as regeneration-induced cyclin $\mathrm{E} 1$ expression levels. Activation of $\operatorname{RXR} \alpha$ by retinoic acids increased the cyclin $\mathrm{E} 1$ promoter activity indicating retinoic acidmediated signaling positively controls cyclin $E 1$ gene expression. As many of these observed changes were not documented in the regenerating livers of other nuclear receptor knockout mice, these observed ef- fects may be hepatocyte RXR $\alpha$ specific. (Am J Pathol 2010, 176:733-743; DOI: 10.2353/ajpath.2010.090524)

Liver regeneration induced by two-thirds partial hepatectomy $(\mathrm{PH})$ proceeds along a sequence of distinctive phases and results in a precise reconstitution of the lost liver mass. ${ }^{1}$ Many nuclear receptor-mediated signals have been implicated in the proliferative response in the regenerating liver. Farnesoid $X$ receptor [FXR (also known as Nr1h4)]-dependent bile acid homeostatic signaling is associated with proliferative events leading to the regeneration of the liver. FXR knockout mice show defective regeneration. ${ }^{2}$ Peroxisome proliferator-activated receptor $\alpha($ PPAR $\alpha)$-mediated Ras and Rhoa membrane association plays a key role in early DNA synthesis and cell proliferation. ${ }^{3}$ Disruption of PPAR $\alpha$-mediated lipid signaling pathway transiently impairs the initiation of liver regeneration. ${ }^{4}$ However, other studies show that PPAR $\alpha$ deficiency does not affect liver regeneration following $\mathrm{PH}^{5,6}$ This discrepancy might be in part due to differences in the genetic backgrounds of the mice used. ${ }^{5}$ Pregnane $X$ receptor (PXR, also known as Nr1i2) mediates hepatocyte proliferation during both early and late stages of liver regeneration. Lack of PXR impairs normal progression of liver regeneration. ${ }^{7}$ Delayed hepatocyte proliferation is also noted in constitutive androstane receptor (also known as Nr1i3) knockout mice. ${ }^{2}$

Retinoid $\mathrm{X}$ receptor $\alpha(\mathrm{RXR} \alpha)$ is the most abundant RXR among the three RXR isoforms $(\alpha, \beta$, and $\gamma){ }^{8} \operatorname{RXR} \alpha$ forms dimers with FXR, PPAR $\alpha$, constitutive androstane receptor, and PXR and regulates gene transcription. ${ }^{9}$

Supported by National Institutes of Health grants CA53596 and COBRE P20 RR021940.

Accepted for publication September 29, 2009

Current address of M.G.: Department of Basic Medical Science, School of Medicine, University of Missouri-Kansas City, 2411 Holmes, Kansas City, MO, 64108.

Address reprint requests to Yu-Jui Yvonne Wan, Ph.D., Department of Pharmacology, Toxicology, and Therapeutics, University of Kansas Medical Center, 4059 Kansas Life Sciences Innovation Center, 3901 Rainbow Blvd, Kansas City, KS 66160. E-mail: ywan@kumc.edu. 
Table 1. Nucleotide Sequences of TagMan Probes (with 5'-FAM and 3'-BHQ1 Modifications) and Primers for the Studied Genes

\begin{tabular}{|c|c|c|c|}
\hline Genes & Probe sequence & Forward primer & Reverse primer \\
\hline Acox1 & $5^{\prime}-$ TGGGACCCACAAGCCTCTGCCA-3' & 5'-TTTGTTGTCCCTATCCGTGAGA-3' & 5'-GCCGATATCCCCAACAGTGA-3' \\
\hline Actb ( $\beta$-actin) & 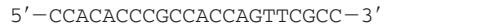 & 5'-CTTCTTTGCAGCTCCTTCGTTG-3' & $5^{\prime}-$ CGACCAGCGCAGCGATATC $-3^{\prime}$ \\
\hline Albumin & 5'-CAAAATGCCATTCTAGTTCGCTACACCCAG-3' & $5^{\prime}-$ ACGAGAAGCTTGGAGAATATGGA $-3^{\prime}$ & 5'-GCCCACTCTTCCTAGGTTTCTTG-3' \\
\hline Arntl (Bmal1) & $5^{\prime}-$ TAGGTCGAATGATCGCGGAGGA $-3^{\prime}$ & $5^{\prime}-$ CAGAGCCGGAGCAGGAAA $-3^{\prime}$ & 5'-AAGGCGATGACCCTCTTATCC-3' \\
\hline CDK2 & 5'-CTTTCTGCCATTCTCACCGTGTCCTTCA-3' & 5'-TCCCCTCATCAAGAGCTATCTGTT-3' & 5'-TCTGCATTGATAAGCAGGTTCTG-3' \\
\hline Cyclin A2 & $5^{\prime}-$ AAACAGAGTGTGAAGATGCCCTGGCTTTT-3' & $5^{\prime}-$ GAAGAGGCCAGCTGAGCTTAAA-3' & $5^{\prime}-$ CGGGTAAAGAGACAGCTGCAT-3' \\
\hline Cyclin B1 & $5^{\prime}-$ TGAACTTCAGCCTGGGTCGCCC $-3^{\prime}$ & $5^{\prime}$-GACAGATGGAGATGAAGATTCTCAGA - 3' & $5^{\prime}$ - ACGTCAACCTCTCCGACTTTAGA-3' \\
\hline Fabp1 & $5^{\prime}-$ TCACCATCACCTATGGACCCAAAGTGG $-3^{\prime}$ & $5^{\prime}-$ TGCATGAAGGGAAGAAAATCAAA - 3' & $5^{\prime}-$ CCCCCAGGGTGAACTCATT $-3^{\prime}$ \\
\hline Fgf2 & $5^{\prime}-\mathrm{CGCGAGAAGAGCGACCCACACG-3^{ \prime }}$ & $5^{\prime}-$ GACGGCCGCGTGGAT $-3^{\prime}$ & $5^{\prime}$-CTCTCTTCTGCTTGGAGTTGTAGTTTG-3' \\
\hline Hgf $\alpha$ & 5'-TGGCATCAAATGCCAGCCTTGGAA-3' & 5'-AAGGGACGGTATCCATCACTAAGA-3' & 5'-GGGTTGAAGGCACGACACAT-3' \\
\hline $\operatorname{Nr} 1 d 1$ (Rev-erb $\alpha)$ & $5^{\prime}-$ CCCATGGACGCAGCGGCC $-3^{\prime}$ & $5^{\prime}-$ GCAAGGCAACACCAAGAATGT - 3' & $5^{\prime}-$ CTTCCCAGATCTCCTGCACAGT-3' \\
\hline$P 21$ & $5^{\prime}-$ ACATTCAGAGCCACAGGCACCATGTC $-3^{\prime}$ & $5^{\prime}-$ GCAGATCCACAGCGATATCCA-3' & $5^{\prime}-$ GGTCGGACATCACCAGGATT $-3^{\prime}$ \\
\hline Ppar $\alpha$ & $5^{\prime}-$ TCTGTCGGGATGTCACACAATGCAATTC $-3^{\prime}$ & $5^{\prime}$-GATTCAGAAGAAGAACCGGAACA-3' & 5'-TGCTTTTTCAGATCTTGGCATTC-3' \\
\hline $\operatorname{Tgf} \alpha$ & $5^{\prime}-$ CCTGGTGGTGGTCTCCATTGTGGC $-3^{\prime}$ & $5^{\prime}-$ CCAGAAGAAGCAAGCCATCACT-3' & 5'-GTGGATCAGCACACAGGTGATAA - 3' \\
\hline Wee1 & 5'-TTTCCAAAGCGCGAGTTATTGAT-3' & $5^{\prime}-\mathrm{GCCGCACACTCCCAAGAG-3^{ \prime }}$ & 5'-AGAACTACCCCGGAGTTTAACAGA-3' \\
\hline
\end{tabular}

Lack of $\mathrm{RXR} \alpha$ impairs activation of its partners and subsequently affects the downstream cascades. In addition, $\mathrm{RXR} \alpha$ forms homodimers and heterodimers with retinoic acid receptors. $\mathrm{RXR} \alpha$ is essential in the transduction of a retinoid signal required for myocardial development and ocular morphogenesis, suggesting that $\mathrm{RXR} \alpha$ is critical for cell proliferation and differentiation. ${ }^{10}$ Lack of $\mathrm{RXR} \alpha$ results in a transient delay in liver growth during embryonic development. ${ }^{11}$ In the current study, we investigated the modulation of liver regeneration by $\operatorname{RXR} \alpha$ and the underlying mechanisms involved.

\section{Materials and Methods}

\section{Animals and $\mathrm{PH}$}

Age and genetic background (mixed background of C57/ BI/6, 129/SvEvTac, and DBA-2) matched wild-type and hepatocyte $\mathrm{RXR} \alpha$-deficient mice (3 to 4 months old) were used for partial hepatectomy. Hepatocyte $R X R \alpha$-deficient mice were generated by deletion of exon 4 of the $R X R \alpha$ gene using albumin-cre/lox-mediated recombination. ${ }^{12}$ The control mice had RXR $\alpha$ loxP/loxP (cre negative) genotype. The mice were housed with a 12:12 hour light/ dark cycle. Standard two-thirds liver resection was performed at 10:00 AM according to the procedure described by others. ${ }^{13}$ Sham-operated mice were included as controls. Mice were sacrificed at the indicated time points and liver samples were immediately excised, snapped frozen in liquid nitrogen, and stored at $-80^{\circ} \mathrm{C}$ until analysis. Liver samples were also fixed in $10 \%$ buffered formalin for immunohistochemistry. All of the animal experiments were conducted in accordance with the National Institutes of Health Guide for the Care and Use of Laboratory Animals.

\section{Ki-67 Immunostaining}

Ki-67 immunostaining was performed using primary Ki-67 antibody (NeoMarkers, Fremont, CA) according to the manufacturer's instruction to monitor hepatocyte proliferation. The number of Ki-67-labeled nuclei was determined by counting the Ki-67-positive hepatocytes in at least five microscope fields $(\times 20)$ for each sample with $n=3$ to 6 mice/time point.

\section{Quantitation of mRNA by Real-Time Polymerase Chain Reaction}

Hepatic RNA isolated using TRIzol (Invitrogen, Carlsbad, CA) was used for reverse transcription followed by amplification of cDNA using the ABI Prism 7900 sequence detection system (Applied Biosystems, Foster City, CA). Primers and probes were designed using Primer Express 2.0 according to the manufacturer's instructions (Table 1). Real-time PCR amplification of cDNA was performed using total RNA (15 ng) in a reaction mixture $(12 \mu \mathrm{l})$ containing TaqMan Universal Master Mix (1X), primers (900 nmol/L each), and FAM-BHQ1 dual-labeled probe $(250 \mathrm{nmol} / \mathrm{L})$. The amplification reactions (with three replicates for each real-time PCR run) were performed with initial hold steps $\left(50^{\circ} \mathrm{C}\right.$ for 2 minutes, followed by $95^{\circ} \mathrm{C}$ for 10 minutes) and 40 cycles of a two-step PCR $\left(92^{\circ} \mathrm{C}\right.$ for $15 \mathrm{~s}, 60^{\circ} \mathrm{C}$ for 1 minute). The mRNA level of target gene normalized to an endogenous control ( $\beta$-actin was used as endogenous reference for hepatocyte growth factor (HGF), fibroblast growth factor (FGF)2, platelet-derived growth factor (PDGF), cyclin-dependent kinase (CDK)1, transforming growth factor (TGF) $\alpha, \operatorname{PPAR} \alpha$, acyl-coenzyme A oxidase 1 (Acox1), liver fatty acid binding protein 1 (Fabp1), stearoyl-CoA desaturase 1 (Scd1), Cry1, and Wee I, while albumin was used as endogenous reference for brain and muscle Arnt-like protein 1 (Bmal1), Reverb $\alpha$, P21, Cry2, Per1, CDK2, cyclin A2, and cyclin B1) and relative to a calibrator (the sham-operated mice of the first studied time point in each figure) was calculated by a comparative cycle threshold $\left(\mathrm{C}_{\mathrm{T}}\right)$ method using a formula: $2^{-\Delta \Delta C T}$, where $\Delta \mathrm{C}_{\mathrm{T}}=\mathrm{C}_{\mathrm{T}}$ Target $-\mathrm{C}_{\mathrm{T}}$ Endogenous control; $\Delta \Delta \mathrm{C}_{\mathrm{T}}=\Delta \mathrm{C}_{\mathrm{T}}$ Experimental group $-\Delta \mathrm{C}_{\mathrm{T}}$ Calibrator (Chemistry Guide, Real-time PCR systems, Applied Biosystems, Foster City, CA). Three to six mice were included at each time point.

\section{Western Blotting}

Liver protein (50 to $200 \mu \mathrm{g}$ ) was electrophoresed and transferred to polyvinylidene difluoride membranes. ${ }^{7,14}$ After incubation with primary antibodies (1:1000 dilution) at $4^{\circ} \mathrm{C}$, blots were incubated with peroxidase-conjugated secondary antibodies (1:4000 dilution). Immune complexes were visualized by enhanced chemiluminescence 
system (Pierce, Rockford, IL). The intensities of the bands were quantified by densitometry with normalization to $\beta$-actin protein level using the Quantity One 1-D Analyzer Software (Bio-Rad Laboratories, CA). Antibodies used included: cyclin D1 (DCS6) and Cdk4 (DCS156) from Cell Signaling Technology, MA; Cdk1 P34(17) and cyclin E1 (M-20) from Santa Cruz Biotechnology (CA); and $\beta$-actin from Abcam (Cambridge, MA).

\section{Plasmid Constructs}

The10-kb regulatory region (containing two DR-1 elements) from the transcription start site of the cyclin E1 gene was subcloned into the pGL3 basic luciferase reporter plasmid (Promega Corporation, Madison, WI). PCR was performed with Accu Taq LA DNA Polymerase (Sigma, St. Louis, MO) using sequence-specific primers containing splice sites for Mlul and Xhol. The forward primer was 5'-ATGCACGCGTCACTAGGGCTGGCAGACAAG-3' containing a Mlul restriction site (bold) and the reverse primer was 5'-GCATCTCGAGCGGAGTTAAGAACCCGTCAT-3' containing an Xhol site (bold) for subsequent directional cloning. The PCR product was gel purified, digested with the appropriate restriction enzymes, and ligated into the pGL3-basic plasmid, which was cleaved with the same restriction enzymes. In addition, annealed oligonucleotides containing the putative nuclear receptor binding sites [-AGGTCAAATGTCA $-(-9036$ to -9048$)$ ] and [-AGGTCAAAGGTGG - -5947 to -5959$)$ ] were inserted into XholBglll digested pGL4.74 [hRluc/TK] vector (Promega Corporation, Madison, WI).

\section{Transient Transfection and Luciferase Activity}

Huh7 cells were maintained in Dulbecco's modified Eagle's medium (Invitrogen) supplemented with 5\% fetal calf serum (Biomeda, Foster City, CA) and $100 \mathrm{U} / \mathrm{ml}$ penicillin/streptomycin. Approximately $4 \times 10^{8}$ cells per well were plated onto 24 -well plates and cultured at $37^{\circ} \mathrm{C}$ in $5 \% \mathrm{CO}_{2}$ with a relative humidity of $95 \%$. The plated cells were allowed to recover for 1 day before transfection with various reporter vectors and expression plasmids of $\operatorname{RXR} \alpha$ alone or $\operatorname{RXR} \alpha$ plus PPAR $\alpha$ (provided by Dr. Ronald Evans, Salk Institute, CA) using Lipofectamine 2000 transfection reagent (Promega Corporation, Madison, WI). The tk-(CRBPII)-Luc (provided by Dr. Ronald Evans, Salk Institute, CA) and tk-(PPRE)-Luc (provided by Dr Frank J. Gonzalez, National Cancer Institute, NIH, $M D$ ) vectors served as positive controls for activation of $\mathrm{RXR} \alpha$ homodimer and $\mathrm{RXR} \alpha-\mathrm{PPAR} \alpha$ heterodimer, respectively. For each transfection, herpes simplex virus thymidine kinase promoter-driven Renilla reniformis luciferase was used as an internal control for normalization. After transfection, cells were treated with dimethyl sulfoxide $(0.1 \%)$, 9-cis-retinoic acid (9-cis-RA), all-trans RA, 13-cis-RA, as well as Wy-14.643 (10 $\mu \mathrm{mol} / \mathrm{L})$. Fresh medium containing ligand was provided every 24 hours. Forty-eight hours after treatment, firefly and Renilla luciferase activities were measured sequentially using a DualLuciferase Reporter assay system (Promega, Madison,
WI) in a single tube TD20/20 luminometer according to the manufacturer's instructions.

\section{Statistical Analysis}

Data are presented as means \pm SD $(n=3-6)$. Statistical analysis was performed using unpaired Student's $t$-tests. Statistical significance was taken at the $P<0.05$ level.

\section{Results}

\section{Impaired Hepatocyte Proliferation in Hepatocyte $R X R \alpha$-Null Mice after PH}

To examine the effect of hepatocyte RXR $\alpha$ on hepatocyte proliferation, Ki-67 immunostaining was performed on liver sections obtained from mice 24 to 120 hours after PH (Figure 1A). Few proliferating cells were noted 24 hours after $\mathrm{PH}$. The number of Ki-67-positive hepatocytes in wild-type mouse livers rapidly increased, and peaked at 36 hours after liver resection (Figure 1B). Proliferation of hepatocytes remained at its peak level until 56 hours and then gradually decreased. In contrast, in regenerating RXR $\alpha$-null mouse livers, hepatocyte proliferation peaked at 68 hours after $\mathrm{PH}$ and sustained at a high level until 72 hours, then decreased. There was proximal 1-day delay in hepatocyte proliferation due to $\operatorname{RXR} \alpha$ deficiency; significant higher numbers of proliferating cells were observed in regenerating wild-type than $\mathrm{RXR} \alpha$-null mouse livers from 36 to 56 hours. Consistently, 36 hours after PH, wild-type mice had an increased liver-to-body weight ratio $(2.70 \%)$ than mutant mice did $(2.28 \%)$. However, liver-to-body weight ratio was not significantly different at 48 and 56 hours after PH (Figure 1C). At 72 hours post$\mathrm{PH}, \mathrm{RXR} \alpha$-null mouse livers had more Ki-67-positive cells than wild-type mouse livers did, likely leading to the slightly larger liver mass observed in $\mathrm{RXR} \alpha$-null mice at this time point. The liver-to-body weight ratio in wild-type and mutant mice was $3.34 \%$ and $3.84 \%$, respectively, at 72 hours. Since liver mass could also be affected by fat accumulation or cell hypertrophy, Ki-67-labeling might be more reliable to monitor cell proliferation and liver growth. These data indicated that hepatocyte proliferation was shifted 24 hours later due to hepatocyte RXR $\alpha$ deficiency.

\section{Impaired Growth Factor Signaling Pathways in Regenerating Hepatocyte RXR $\alpha$-Null Mouse Livers}

HGF is crucial for liver regeneration. After PH, HGF is activated very early and intrahepatic HGF is consumed within the first 3 hours, followed by new HGF synthesis from 3 to 48 hours. ${ }^{15}$ In addition, other growth factors including FGF2, PDGF, and TGF $\alpha$ have also been implicated in hepatocyte proliferation during liver regeneration. ${ }^{16-19}$ The impact of RXR $\alpha$ deficiency on the expression of these growth factors was studied during liver regeneration. Our data showed that in contrast to wildtype mouse livers, in which HGF mRNA induction oc- 
A

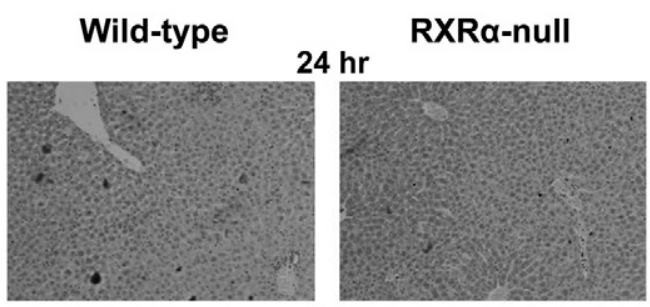

$48 \mathrm{hr}$

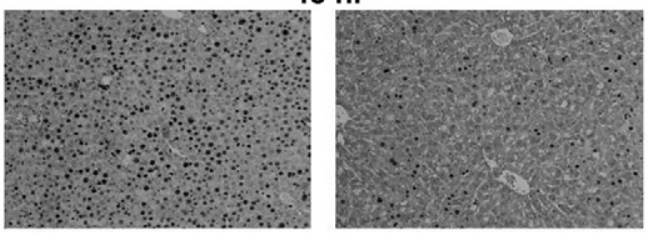

$68 \mathrm{hr}$

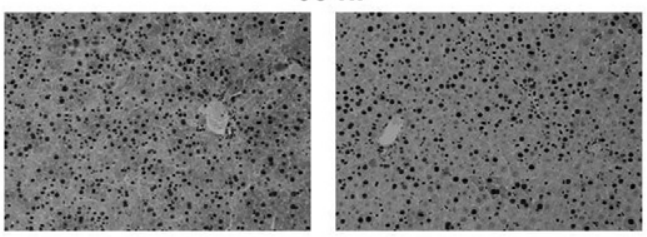

$120 \mathrm{hr}$
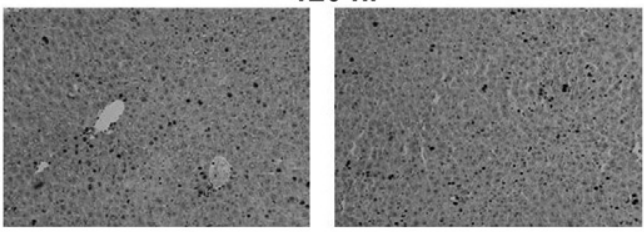

B

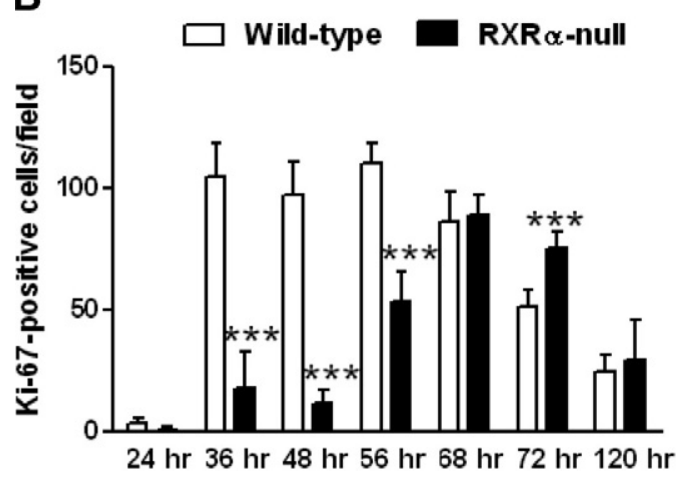

Wild-type

$36 \mathrm{hr}$ RXRa-null

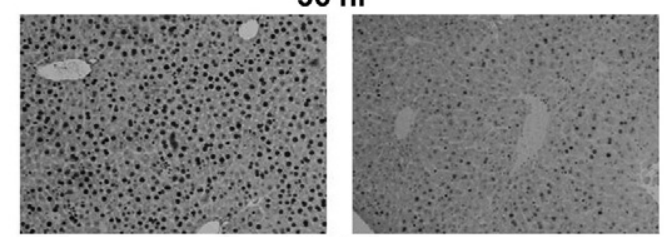

$56 \mathrm{hr}$

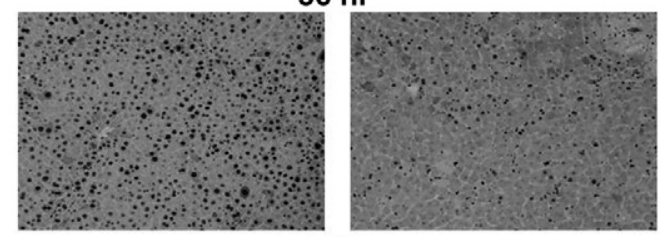

$72 \mathrm{hr}$
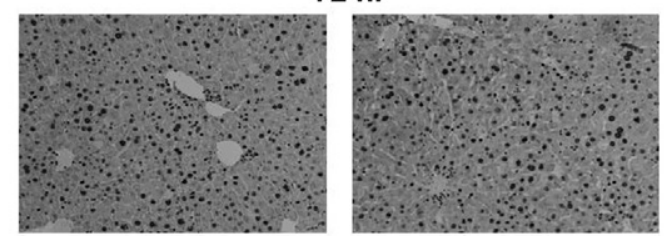

C

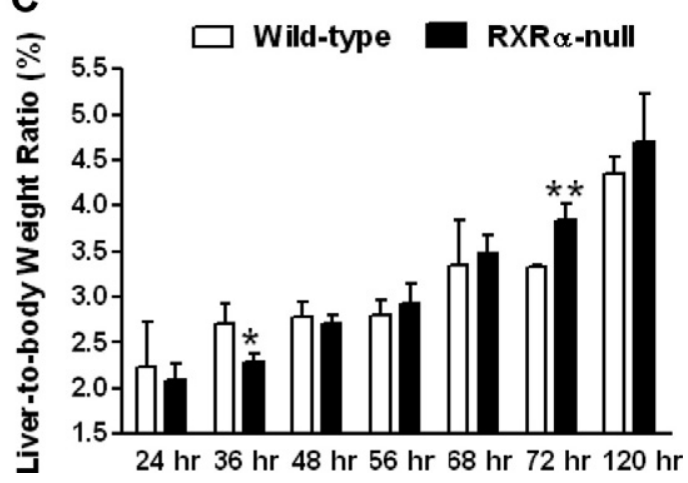

Figure 1. Defective hepatocyte proliferation in hepatocyte $R X R \alpha$-null mice after PH. A: Representative of Ki-67 immunostaining in wild-type and $R X R \alpha$-null mouse livers at indicated time points after PH. B: Quantification of Ki-67-positive hepatocytes in at least five microscope fields ( $\times 20$ optical field). C: Liver-to-body weight ratio (\%). Results were expressed as mean $\pm \mathrm{SD}\left(n=3\right.$ to 6 mice/group). ${ }^{*} P<0.05,{ }^{* * *} P<0.01$, ${ }^{* * * *} P<0.001$, versus wild-type mice.

curred 3.5 hours after $\mathrm{PH}$, the induction of HGF mRNA in the mutant mice took place 56 hours after $\mathrm{PH}$, which might account for the delayed proliferation found 72 hours after $\mathrm{PH}$ (Figure 2A). Consistently, protein level of HGF was induced in wild-type mouse livers, but not in $\mathrm{RXR} \alpha$-null livers, 3.5 hours post $\mathrm{PH}$ (Figure 2B). In addition, mRNA levels of HGF were lower in regenerating $\mathrm{RXR} \alpha$-null livers than regenerating wild-type mouse livers 0.5 and 3.5 hours after $\mathrm{PH}$ (Figure 2A). Induction of the expression of FGF2 and PDGF genes was observed in wild-type mouse livers at 56 hours and 48 hours after $\mathrm{PH}$, respectively, but not in regenerating $\mathrm{RXR} \alpha$-null mouse livers. Additionally, when wild-type hepatocytes were actively proliferating (48 and 56 hours after $\mathrm{PH}$ ), the levels of FGF2 and PDGF mRNA were significantly higher in re- generating wild-type than mutant mouse livers (Figure 2, $\mathrm{C}$ and $\mathrm{D}$ ). Thus, these changes in gene expression might be in part responsible for the delayed hepatocyte proliferation observed in hepatocyte $\mathrm{RXR} \alpha$-null livers.

In contrast to HGF, FGF2, and PDGF, which had a delayed induction in regenerating mutant mouse livers, the induction of TGF $\alpha$ mRNA was consistently found in $\mathrm{RXR} \alpha$-null mouse livers 48, 56, 68, and 72 hours after $\mathrm{PH}$; whereas TGF $\alpha$ induction was only noted at 56 hours after $\mathrm{PH}$ in wild-type mouse livers. Furthermore, significantly higher mRNA levels of TGF $\alpha$ were found due to lack of $\mathrm{RXR} \alpha 48$ and 72 hours after $\mathrm{PH}$ (Figure 2E). These data suggested that TGF $\alpha$ might play a more important role in stimulating hepatocyte proliferation in $\mathrm{RXR} \alpha$-null mice. Additional study is needed to define the role and the 
A

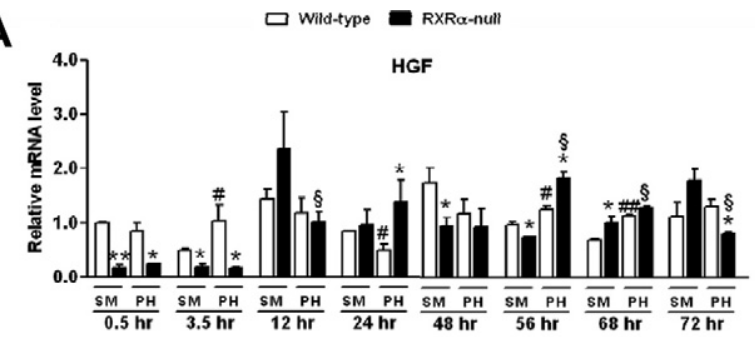

B
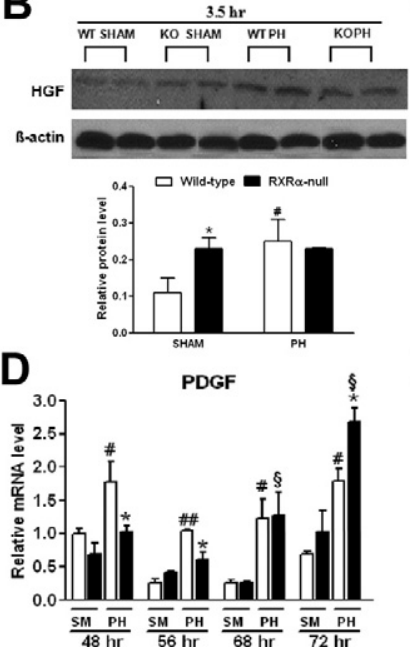

C

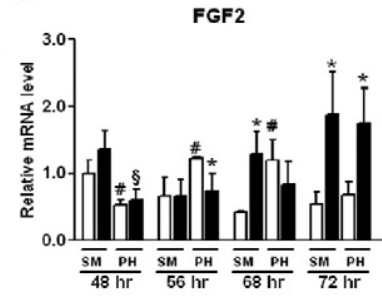

E

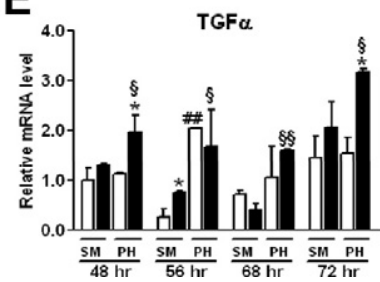

Figure 2. Aberrant growth factor expression in regenerating $\mathrm{RXR} \alpha$-null (KO) mice after PH. Temporal profile of HGF mRNA level (A), HGF protein level at 3.5 hours (B), and temporal profiles of mRNA levels for FGF2 (C), PDGF (D), and TGF $\alpha$ (E) after sham and PH operation were assessed by real-time PCR and Western blot. Results were expressed as mean \pm SD ( $n=3$ to 6 mice/group). $\beta$-actin was used as endogenous reference for HGF, FGF2, PDGF, and TGF $\alpha .{ }^{*} P<0.05,{ }^{* *} P<0.01$ versus wild-type mice. ${ }^{*} P<0.05$, ${ }^{\# \#} P<0.01$ versus sham-operated wild-type mice. ${ }^{\mathbb{S}} P<0.05,{ }^{\mathbb{S}} P<0.01$, versus sham-operated $\mathrm{RXR} \alpha$-null mice. $\mathrm{SM}=$ sham; $\mathrm{PH}=$ partial hepatectomy; WT $=$ wild-type; $\mathrm{KO}=\mathrm{RXR} \alpha$-null.

underlying mechanisms. These findings indicate multiple signaling pathways orchestrate liver regeneration; when one pathway is compromised, the other pathways will be activated to compensate for the missing signaling. The elevated mRNA levels of HGF at 56 hours, FGF2 and PDGF at 72 hours, and sustained higher levels of TGF $\alpha$ at 48 and 72 hours in RXR $\alpha$-null livers might account for the delayed hepatocyte proliferation occurred in $\mathrm{RXR} \alpha$-null mice.

It is important to note that no impaired growth factor signaling was documented in other nuclear receptor knockout mice during liver regeneration indicating the observed phenomenon in the current study might be hepatocyte $\operatorname{RXR} \alpha$ specific (Table 2). ${ }^{2-4,7}$

\section{Impaired Circadian Clock-Controlled Cell Cycle Progression in Regenerating $R X R \alpha$-Null Livers}

Studies have indicated that progression through the cell cycle occurs at specific times of the day/night cycle and hepatic circadian clockwork participates in liver regeneration by controlling the cell-division cycle. ${ }^{20,21}$ In addition, there are direct interactions of $\operatorname{RXR} \alpha$ and $\operatorname{RAR} \alpha$ with clock and clock-like protein MOP4, which negatively regulates clock/MOP4: Bmal1-mediated clock gene expression in vascular cells. ${ }^{22}$ To test whether RXR $\alpha$ is required for hepatocyte proliferation via affecting circadian clockmediated cell cycle division, we examined the mRNA expression profiles of circadian clock genes in both regeneration wild-type and $\operatorname{RXR} \alpha$-null mouse livers.

\section{Deregulation of PPAR $\alpha / B m a / 1 / R e v-e r b \alpha / P 21$ Pathway due to RXR $\alpha$ Deficiency}

Bmal1, which is a core clock regulator, is critical for cyclin-dependent kinase inhibitor 1A (P21) expression through the Rora/Rev-erb $\alpha$ pathway. ${ }^{20}$ P21 negatively regulates $\mathrm{G} 1$ phase progression. ${ }^{20} \mathrm{~A}$ decreased proliferation was observed in Bmal1-null primary hepatocytes, which have elevated levels of P21. ${ }^{20}$ PPAR $\alpha$ is a direct regulator of Bmal1 expression in the liver via its direct binding to the Bmal1 promoter. ${ }^{23}$ Impaired cell cycle gene regulation was reported in $\operatorname{PPAR} \alpha$-null mouse liver, but whether the delay was due to altered Bmal1-mediated signaling was not established. ${ }^{3,4}$ Since RXR $\alpha$ is an essential partner of PPAR $\alpha$, we hypothesize that impaired liver regeneration in $\operatorname{RXR} \alpha$-null mice is in part due to deregulation of the PPAR $\alpha /$ Bmal1/Rev-erb $\alpha /$ P21/cell cycle pathway.

Table 2. The Role of Nuclear Receptor in Liver Regeneration

\begin{tabular}{|c|c|c|c|c|c|}
\hline $\begin{array}{l}\text { Nuclear receptor } \\
\text { knockout mice }\end{array}$ & Liver regeneration & Growth factor & Circadian clock & Cell cycle & Reference \\
\hline $\mathrm{RXR} \alpha$ (current study) & Delayed & Dependent & Dependent & Dependent & \\
\hline $\mathrm{RXR} \alpha$ & $\begin{array}{l}\text { Liver necrosis occurred due to lack } \\
\text { of } \mathrm{RXR} \alpha \text {. Increased } \mathrm{BrdU} \text { positive } \\
\text { hepatocytes after } \mathrm{PH}\end{array}$ & NR & NR & NR & 29 \\
\hline FXR & Delayed & Independent & NR & NR & 2 \\
\hline PXR & Delayed & NR & NR & NR & 7 \\
\hline PXR & Not delayed & NR & NR & NR & 2 \\
\hline $\operatorname{PPAR} \alpha$ & Delayed & NR & NR & $\begin{array}{c}\text { Cdk2 and Cdk4 } \\
\text { P21 and P27 }\end{array}$ & 3 \\
\hline $\operatorname{PPAR} \alpha$ & Delayed & NR & NR & Cyclin D1 & 4 \\
\hline PPAR $\alpha$ & Not delayed & NR & NR & NR & 5,6 \\
\hline $\operatorname{PPAR} \alpha$ & $\mathrm{NR}$ & NR & Bmal1 & NR & 20 \\
\hline CAR & Delayed & NR & NR & NR & 2 \\
\hline
\end{tabular}

NR, not reported. 
To test this hypothesis, the expression of PPAR $\alpha$ gene was studied during liver regeneration. At 48 hours after $\mathrm{PH}$, while the wild-type hepatocytes were actively proliferating, the level of PPAR $\alpha$ mRNA reached its peak. This finding indicates the importance of PPAR $\alpha$ at this particular time point during regeneration. To monitor the activation of PPAR $\alpha$, we studied the expression of PPAR $\alpha$ target genes Acox1, liver Fabp1, and Scd1. ${ }^{24,25}$ Fabp1 mRNA level in sham-operated mice was reduced due to $\mathrm{RXR} \alpha$ deficiency, which was consistent with the basal level change without any treatment reported in our previous publication. ${ }^{12}$ In contrast to our previous finding, which showed the basal PPAR $\alpha$ mRNA levels were increased by twofold due to hepatocyte RXR $\alpha$ deficiency, the current study does not observe significant changes in $P P A R \alpha$ mRNA levels because of RXR $\alpha$ deficiency. Since PPAR $\alpha$ is a circadian gene, ${ }^{26}$ the variation of PPAR $\alpha$ mRNA level might be due to the timing when the mice were sacrificed. Forty-eight hours after $\mathrm{PH}, \mathrm{mRNA}$ levels of Acox1 (3.2-fold), Fabp1 (1.9-fold), and Scd1 (9.2-fold) were up-regulated in wild-type mouse livers, but not in RXR $\alpha$-null livers. As a result, mRNA levels of Acox1 (2.5fold), Fabp1 (2.4-fold), and Scd-1 (2.7-fold) were significantly higher in regenerating wild-type than regenerating mutant mouse livers at this time point (Figure $3 A$ and $B$ ). The data suggested that PPAR $\alpha$ signaling pathway was activated in wild-type mouse livers at this time point. Consistent with this finding, at the same time point, significant induction of Bmal1 and Rev-erb $\alpha$ was observed in wild-type mouse livers, but not in RXR $\alpha$-null livers, after $\mathrm{PH}$. In addition, Bmal1 and Rev-erb $\alpha$ mRNA levels were significantly higher in the regenerating wild-type than the regenerating $\mathrm{RXR} \alpha$-null livers. However, at the same time point (48 hours after $\mathrm{PH}$ ), the level of p21 mRNA peaked in the regenerating $\mathrm{RXR} \alpha$-null livers and its level was significantly higher than that of regenerating wild-type mouse livers. Thus, G1 phase progression can be compromised due to elevated P21 (Figure 3, C-E). Take together, a compromise of PPAR $\alpha / B m a l 1 / R e v-e r b \alpha / P 21$ pathway in $\mathrm{RXR} \alpha$-null mouse livers might contribute to delayed hepatocyte proliferation.

\section{Deregulation of Cry1/Cry2 Expression due to $R X R \alpha$ Deficiency}

It has been shown that lack of clock activity $\left(\mathrm{Cry}^{-1-}{ }^{-1}\right.$ Cry $2^{-1-}$ double mutant animals) leads to decreased cyclin D1 and increased Wee1 expression levels after PH, and subsequently slows down cell cycle progression. ${ }^{21}$ Thus, Cry $1 / 2$ plays key roles in promoting hepatocyte proliferation. Our data showed the expression patterns of Cry $1 / 2$ mRNA were altered due to lack of hepatocyte RXR $\alpha$ (Figure 3F and G). For example, when the wild-type hepatocytes were actively proliferating after $\mathrm{PH}$, the levels of Cry1 and Cry2 mRNA were significantly higher in wild-type than in $\mathrm{RXR} \alpha$-null mouse livers at 48 hours and 56 hours after $\mathrm{PH}$, respectively. The changes were relatively mild, but the differences reached statistical significance. At 72 hours, RXR $\alpha$-null mouse livers exhibited higher Cry2 mRNA level, which might help the RXR $\alpha$-null hepatocytes to start proliferating (Figure 3, F and G). Although the biological meaning of these changes remains to be studied, these data indicate $R X R \alpha$ might have an impact on clock gene expression.

\section{Deregulation of Wee1/Per1 Expression due to $R X R \alpha$ Deficiency}

Wee 1 is a known Bmal1/clock target gene, whose product inhibits the $G_{2} / M$ transition. ${ }^{21,27}$ When Wee1 reaches its nadir, G2 phase cells enter mitosis, which occurs at ZTO (zeitgeber time, ZTO: light on). ${ }^{21,27}$ Thus, in our study, mitosis peaked around 44 hours (6:00 AM in our study) after surgery, which coincided with the low expression of Wee1 mRNA level observed in regenerating wildtype mouse livers at 48 hours (Figure $3 \mathrm{H}$ ). In regenerating $\mathrm{RXR} \alpha$-null livers, the level of Wee1 mRNA peaked early (48 hours after $\mathrm{PH}$ ), which might cause a delay of G2/M transition and thus reduced cell proliferation at the early studied time points ( 48 and 56 hours). At 68 hours after PH (6:00 AM, ZTO of another diurnal cycle), Wee1 mRNA level reached its nadir in both liver genotypes. However, the hepatic Wee1 mRNA level was higher in wild-type than in $\operatorname{RXR} \alpha$ knockout mice, which might explain the increased cell proliferation found at 72 hours after $\mathrm{PH}$ in the knockout mice. In addition, Per1 has also been demonstrated to be involved in the negative regulation of cell cycle targeting at G2/M transition. ${ }^{28}$ Per1 protein has been indicated to induce the checkpoint kinase 2, which results in inhibition of $\mathrm{CDK} 1 / \mathrm{Cyclin} \mathrm{B} 1$, thus leading to G2/M suppression. ${ }^{20,28}$ Our data showed that Per1 mRNA levels were significantly higher in $\operatorname{RXR} \alpha$-null mouse livers compared with wild-type mouse livers 48 hours after PH (Figure 3l). Thus, impaired hepatocyte proliferation observed in $\mathrm{RXR} \alpha$-null livers at 48 hours after $\mathrm{PH}$ might be in part due to deregulated expression of Wee1 and Per1.

\section{Deregulated Cell Cycle Gene Expression in Regenerating Hepatocyte RXR $\alpha$-Null Mouse Livers}

Interference of growth factors and circadian clock gene expression should have an effect on cell cycle progression. We next studied the impact of $\mathrm{RXR} \alpha$ deficiency on the expression of cell cycle genes in regenerating mouse livers. The expression was studied by real-time PCR and/or Western blot. The focused time points were 48 and 56 hours (at which wild-type and $\mathrm{RXR} \alpha$-null livers showed a striking difference in hepatocyte proliferation by Ki-67 staining) as well as 68 and 72 hours after PH (when RXR $\alpha$-null hepatocytes were actively proliferating).

At 48 hours after PH, cyclin D1 level was induced in regenerating wild-type mouse livers and the level was significantly higher than that in RXR $\alpha$-null livers (Figure $4 A$ ), consistent with higher Cry 1 mRNA level observed in wild-type mouse livers at the same time point (Figure 3F). In addition, RXR $\alpha$ deficiency also resulted in decreased induction of Cdk4 (Figure 4B). Reduced expression of 

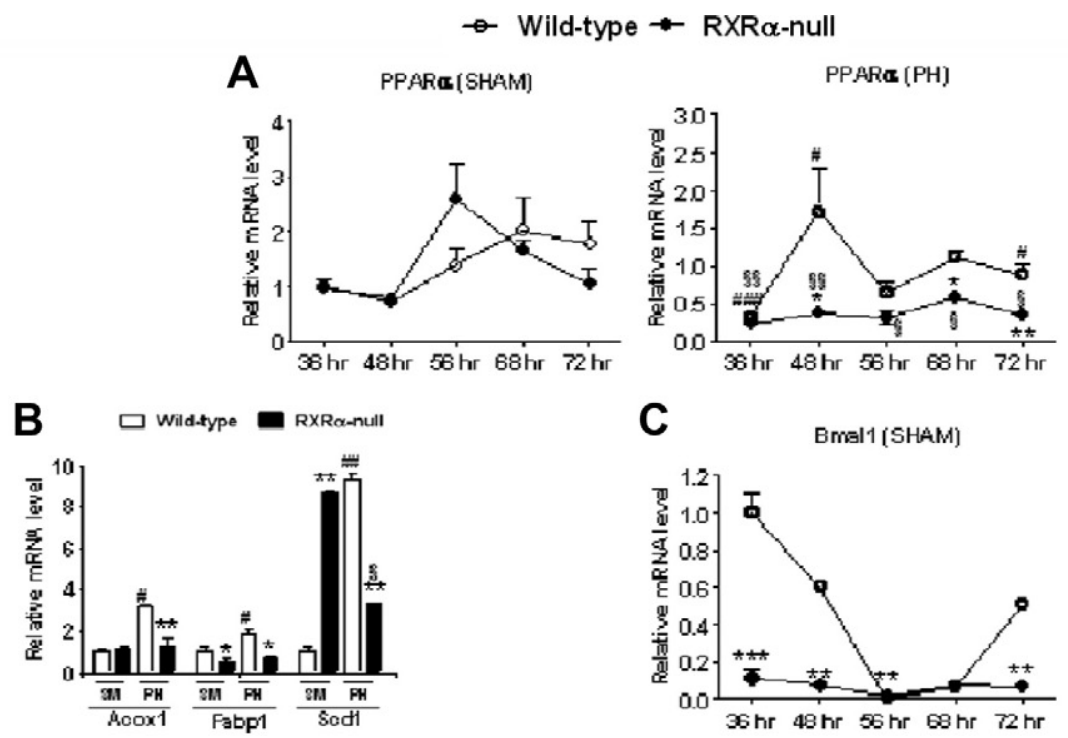

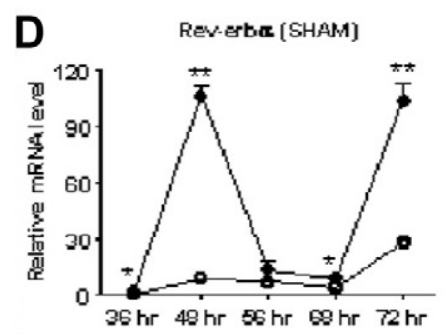

$\mathbf{F}$

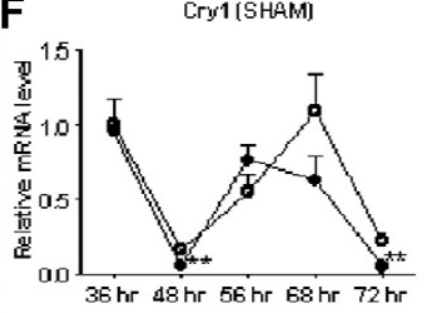

H

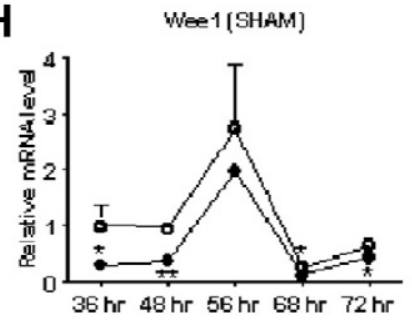

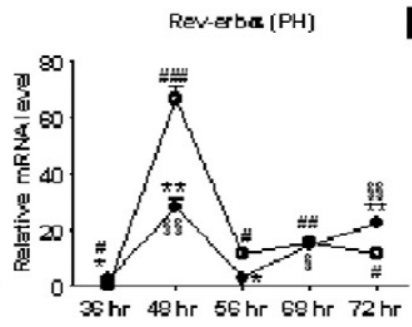

Cry $1(\mathrm{PH})$

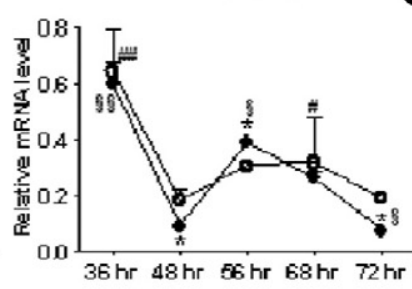

C

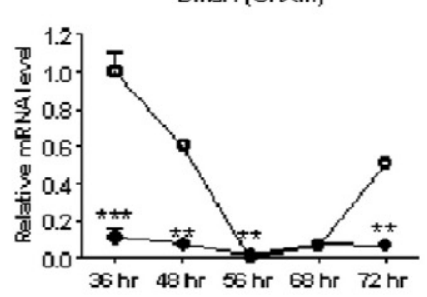

E P21[SHAM]

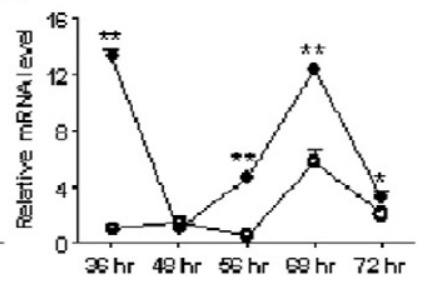

G
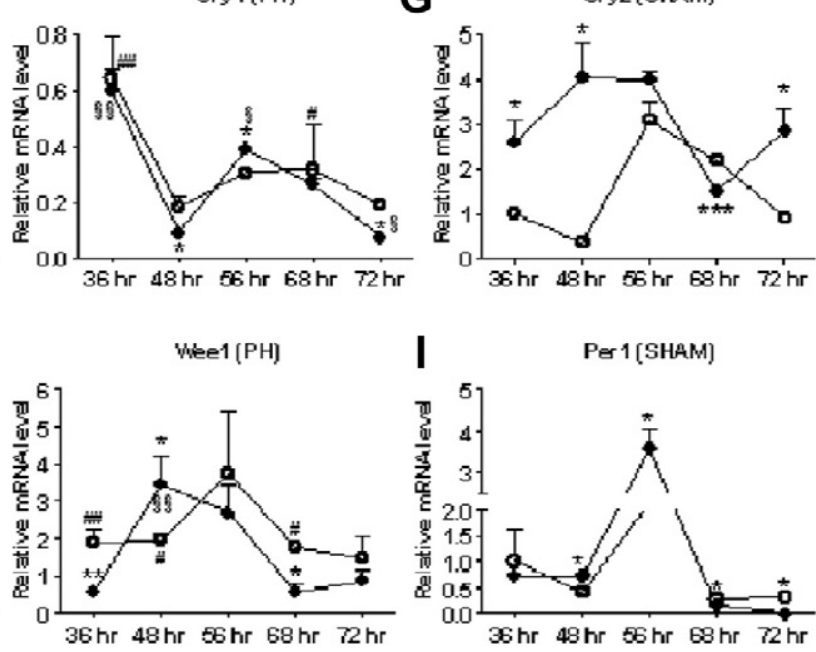

Per 1 [SHAM]

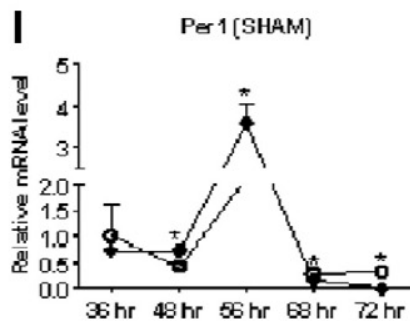

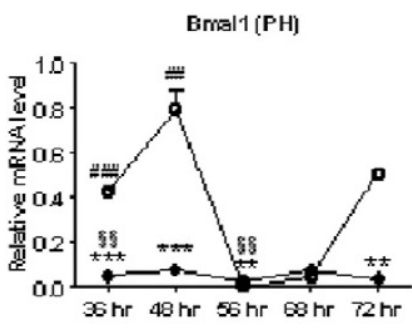

$\mathrm{P} 21[\mathrm{PH}]$

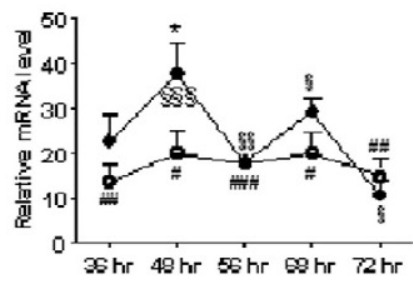

Cry2 $(\mathrm{PH})$

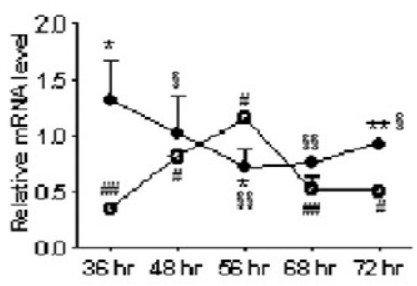

$\mathrm{Pe} 1(\mathrm{FH})$

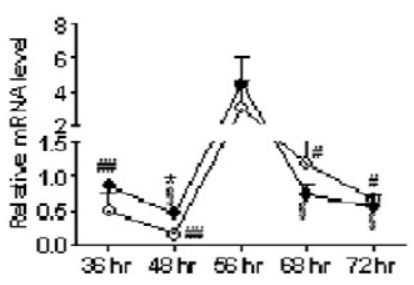

Figure 3. Impaired circadian clock-controlled cell cycle progression in regenerating RXR $\alpha$-null livers. Temporal profile of mRNA level for PPAR $\alpha$ (A) and mRNA levels of PPAR $\alpha$ target genes (Acox1, Fabp1, and Scd1) at 48 hours (B) as well as temporal profiles of mRNA levels for Bmal1 (C), Rev-erb $\alpha$ (D), P21 (E), Cry1 $(\mathbf{F})$, Cry $2(\mathbf{G})$, Wee1 $(\mathbf{H})$, and Per1 (I) after sham and PH operation were assessed by real-time PCR. Results were expressed as mean \pm SD $(n=3$ to 6 mice/group). $\beta$-actin was used as endogenous reference for PPAR $\alpha$, Acox1, Fabp1, Scd1, Cry1, and Wee 1; while albumin was used as endogenous reference for Bmal1, Rev-erb $\alpha$, P21, Cry2, and Per1. ${ }^{*} P<0.05,{ }^{* * *} P<0.01$, and ${ }^{* * *} P<0.001$, versus wild-type mice. ${ }^{*} P<0.05$, ${ }^{\# *} P<0.01$, and ${ }^{\# \# * *} P<0.001$, versus sham-operated wild-type mice. ${ }^{\mathbb{P}} P<0.05,{ }^{\mathbb{S}} P<0.01$, and ${ }^{{ }^{S} P} P<0.001$, versus sham-operated $\mathrm{RXR} \alpha$-null mice. $\mathrm{SM}=$ sham; PH $=$ partial hepatectomy.

cyclin D1 and Cdk4 will definitely hamper the G1 phase progression in $\mathrm{RXR} \alpha$-null livers at 48 hours after $\mathrm{PH}$.

Induction of cyclin E1/Cdk2 was also impaired in regenerating $\mathrm{RXR} \alpha$-null mouse livers. The level of cyclin E1 was significantly induced in regenerating wild-type mouse livers at 48 hours, but not at 72 hours. Surprisingly, at 48 and 72 hours after the surgeries (sham operation and $\mathrm{PH}$ ), cyclin $\mathrm{E} 1$ protein was not detectable in
RXR $\alpha$-null livers (Figure 4C). These data indicated that hepatocyte $\mathrm{RXR} \alpha$ deficiency not only affects the basal cyclin E1 level, but also PH-induced cyclin E1 gene expression. Concurrently, induction of CDK2 mRNA level was observed in regenerating wild-type mouse livers, but not in $\mathrm{RXR} \alpha$-null mouse livers, 48 hours after $\mathrm{PH}$. In addition, Cdk2 mRNA level was much lower in regenerating $\mathrm{RXR} \alpha$-null mouse livers than that in regenerating 

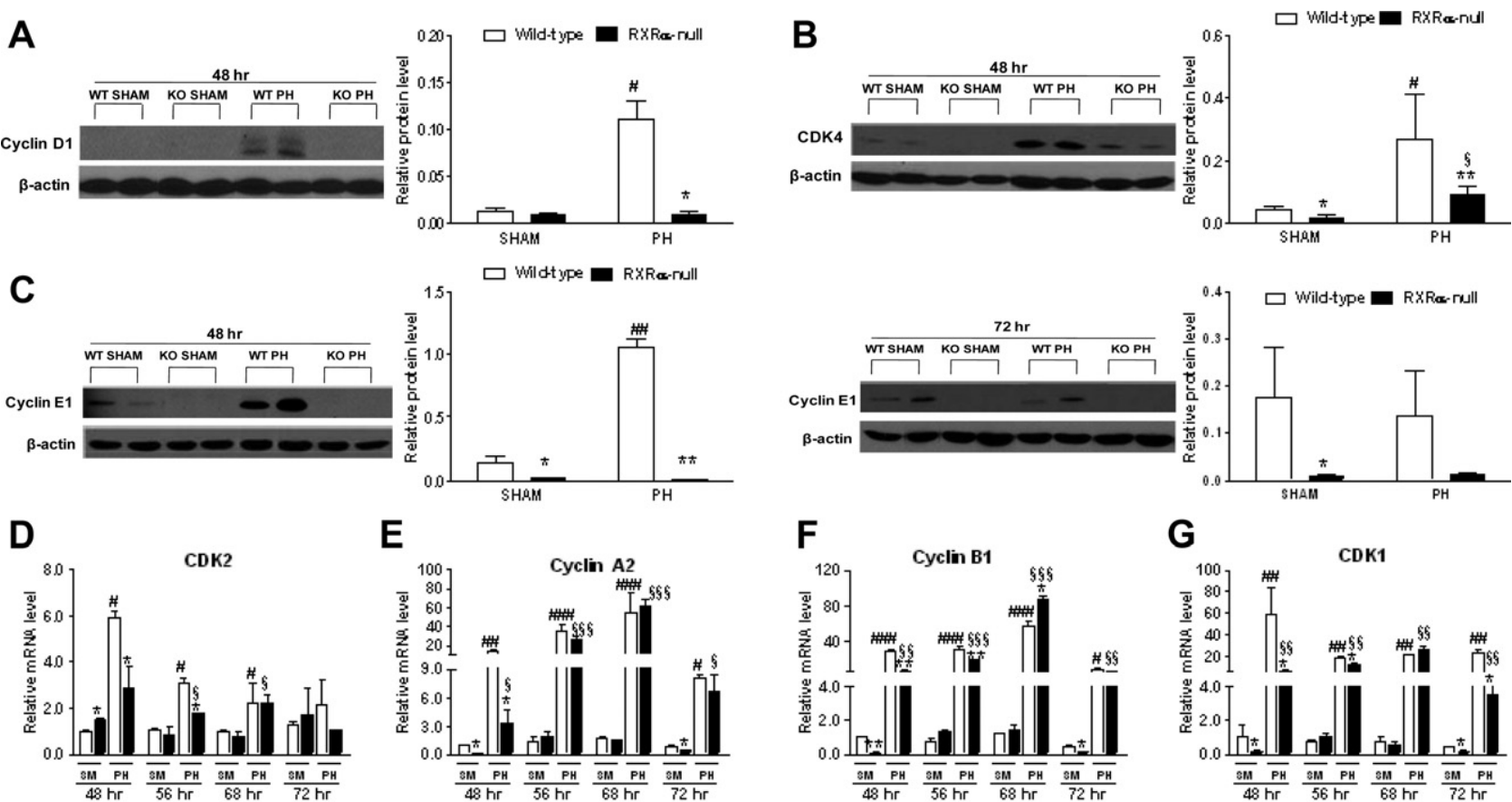

E
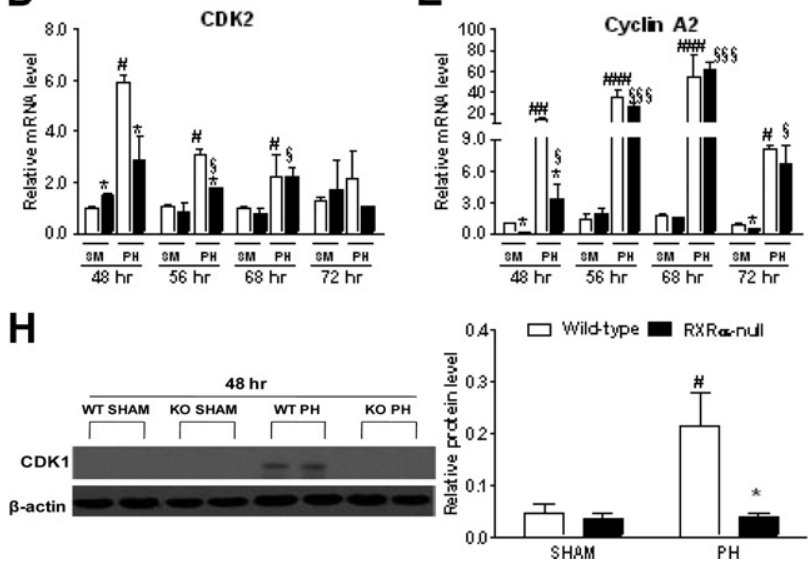
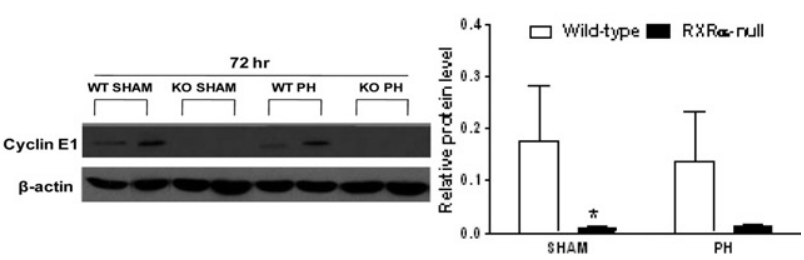

$\mathbf{F}$

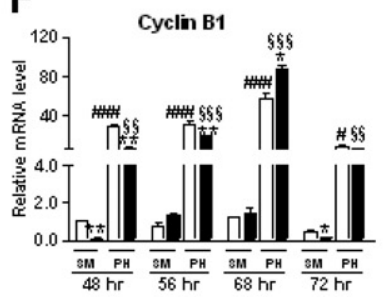

G
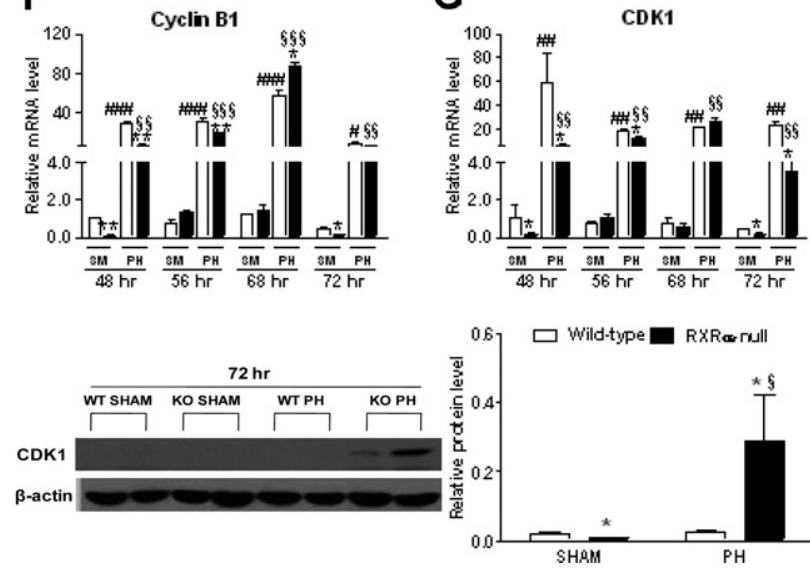

Figure 4. Impaired cell cycle progression in hepatocyte RXR $\alpha$-null (KO) mice after PH. Expressions of cyclin D1 (A), Cdk4 (B), cyclin E1 (C), Cdk2 (D), cyclin A2 (E), cyclin B1 (F), and Cdk1 (G and $\mathbf{H})$ at 48 to 72 hours were assessed by Western blot and/or real-time PCR. Relative protein levels were normalized to $\beta$-actin level of the same blot. Representative results are shown. Results were expressed as mean $\pm \mathrm{SD}$ ( $n=3$ to 6 mice/group). $\beta$-actin was used as endogenous reference for CDK1; while albumin was used as endogenous reference for Cdk2, cyclin A2, and cyclin $\mathrm{B} 1 .{ }^{*} P<0.05,{ }^{* *} P<0.01$, versus wild-type mice. ${ }^{*} P<0.05$, ${ }^{\# \#} P<$

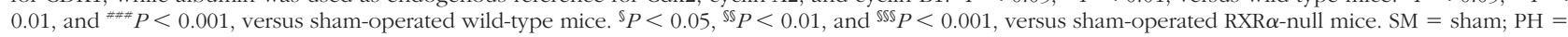
partial hepatectomy; WT $=$ wild-type; $\mathrm{KO}=\mathrm{RXR} \alpha$-null.

wild-type mouse livers at 48 and 56 hours after $\mathrm{PH}$ (Figure 4D). Reduced expression and induction of cyclin E1 and Cdk2 will impair G1-S transition in $\mathrm{RXR} \alpha$-null mouse livers.

A strong induction of cyclin A2 mRNA (11.2-fold) was seen 48 hours after $\mathrm{PH}$ in wild-type mouse livers (Figure $4 \mathrm{E})$. However, in regenerating $\mathrm{RXR} \alpha$-null mouse livers, only a weak induction of cyclin A2 mRNA level was noted at this time point. Also, significant lower cyclin A2 mRNA level was noted in $\mathrm{RXR} \alpha$-null than wild-type mouse livers 48 hours after $\mathrm{PH}$ (Figure 4E), concurrent with reduced Cdk2 mRNA level found in RXR $\alpha$-null livers at the same time point (Figure 4D), which might lead to impaired progression through the S-phase in $\mathrm{RXR} \alpha$-null livers. At later time points (68 and 72 hours after $\mathrm{PH}$ ), no significant difference was observed for hepatic Cdk2 and cyclin A2 mRNA levels between wild-type and $\mathrm{RXR} \alpha$-null regenerating livers.

Delayed or impaired induction of cyclin D1/Cdk4 and cyclin E/Cdk2 as well as cyclin A2/Cdk2, together with deregulation of $\mathrm{PPAR} \alpha / \mathrm{Bmal} 1 / \mathrm{Rev}-\mathrm{erb} \alpha / \mathrm{P} 21$ pathway, might contribute to delayed progression of cells through G1 and S phase, thus resulting in delayed hepatocyte proliferation in $\mathrm{RXR} \alpha$-null mouse livers.
Cyclin A/Cdk1 and cyclin B1/Cdk1 regulate cell cycle progression during G2/M phase. Significantly higher cyclin B1 and CDK1 mRNA levels were observed in regenerating wild-type than in regenerating $\mathrm{RXR} \alpha$-null mouse livers at 48 hours after PH (Figure 4, F and G), concurrent with elevated Cry1 and reduced Wee1 and Per1 mRNA levels in regenerating wild-type livers at the same time point. CDK1 protein levels were also significantly induced in wild-type mouse livers 48 hours after $\mathrm{PH}$ (Figure $4 \mathrm{H}$ ). However, such induction was not detectable in the mutant mouse livers. Thus, the induction of cyclin B1/Cdk1 after $\mathrm{PH}$ might be also hepatocyte $\mathrm{RXR} \alpha$-dependent. Together, reduced expression of cyclin A2/Cdk1 and cyclin B1/Cdk1, as well as elevated expression of Wee1 and Per1, may contribute to delayed hepatocyte proliferation at 48 hours after $\mathrm{PH}$ in $\mathrm{RXR} \alpha$-null mice. Interestingly, the mRNA levels of cyclin B1 were higher in regenerating $\mathrm{RXR} \alpha$-null than wild-type livers at 68 hours, which was accompanied with increased protein level of Cdk1 at 72 hours. The higher expression levels of cyclin B1 and Cdk1 in regenerating mutant mice might allow hepatocytes to start proliferation at later time points.

These results clearly indicate that the expression of many cell cycle-related genes and proteins is deregu- 
lated, which in turn affects cell cycle progression, in regenerating hepatocyte $\mathrm{RXR} \alpha$-null mouse livers.

\section{Positive Regulation of Cyclin E1 Transcription by Retinoic Acid Signaling}

Our data showed that the level of cyclin E1 was reduced due to hepatocyte $\mathrm{RXR} \alpha$ deficiency. In addition, $\mathrm{PH}$ induced cyclin E1 expression was not found during hepatocyte proliferation (48 hours after $\mathrm{PH}$ ) due to hepatocyte $\mathrm{RXR} \alpha$ deficiency (Figure 4C). Thus, we hypothesize that cyclin E1 gene transcription might be regulated by $\mathrm{RXR} \alpha$, which might contribute to liver regeneration. Transient transfection assays were performed to determine whether activation of $\mathrm{RXR} \alpha$ pathway by retinoic acid could regulate the transcription of the cyclin E1 gene.

As shown in Figure 5A, when $\mathrm{RXR} \alpha$ alone was overexpressed, 9-cis-RA and all-trans RA, but not 13-cis-RA, induced the Cyclin E1 promoter driven luciferase activity by 4.2- and 2.1-fold, respectively. In addition, induced reporter activity was observed for -9036DR1-luc construct, but not -5947DR1-luc construct, after 9-cis-RA or all-trans RA treatment. In contrast, 9-cis-RA-mediated induction of luciferase activity was not found when PPAR $\alpha$ plus $\mathrm{RXR} \alpha$ was co-expressed (Figure 5B). Activation of PPAR $\alpha / R X R \alpha$ by $\mathrm{Wy}-14,643$ did not result in induced luciferase activity either. These findings suggest that via $\mathrm{RXR} \alpha$ homodimer, but not PPAR $\alpha / \mathrm{RXR} \alpha$ heterodimer, all-trans RA or 9-cis-RA can directly regulate the transcription of the cyclin E1 gene. In addition, the DR1 motif located at -9036 upstream from the transcription start site of the cyclin E1 gene is responsible for mediating the effect of RA in induction of the cyclin E1 gene. For positive controls, significant induction of luciferase activity for CRBPII-luc and PPRE-luc reporter constructs was observed after 9-cis-RA and Wy-14,643 treatment, respectively.

\section{Discussion}

The present study demonstrates that hepatocyte $\mathrm{RXR} \alpha$ is required for signaling pathways involved in liver regeneration. The following summarizes our findings: (1) RXR $\alpha$ deficiency results in a delay in hepatocyte proliferation; (2) growth factor-mediated signaling pathways are altered because of hepatocyte $\mathrm{RXR} \alpha$ deficiency, which in part contributes to delayed cell proliferation; (3) lack of $\mathrm{RXR} \alpha$ also resulted in impaired cell cycle progression due to suppressed activation of cell cycle regulators and deregulation of circadian clock-mediated cell division; and (4) via $\mathrm{RXR} \alpha$ homodimer, but not $\mathrm{RXR} \alpha / \mathrm{PPAR} \alpha$ heterodimer, all-trans RA and 9-cis-RA can positively regulate the transcription of the cyclin E1 gene. Thus, lack of $\mathrm{RXR} \alpha$ delayed normal progression of hepatocyte proliferation in response to liver mass loss. At later stages (72 hours after $\mathrm{PH}$ ), $\mathrm{RXR} \alpha$ signaling is compensated by other mechanisms and hepatocyte proliferation is observed in hepatocyte $\mathrm{RXR} \alpha$-null mice, which supports the notion

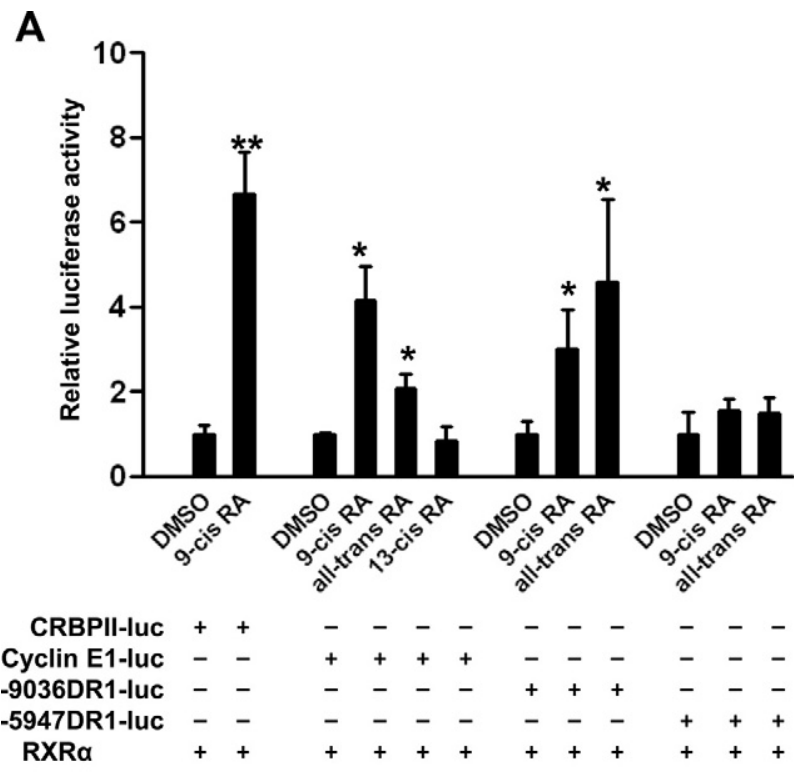

B

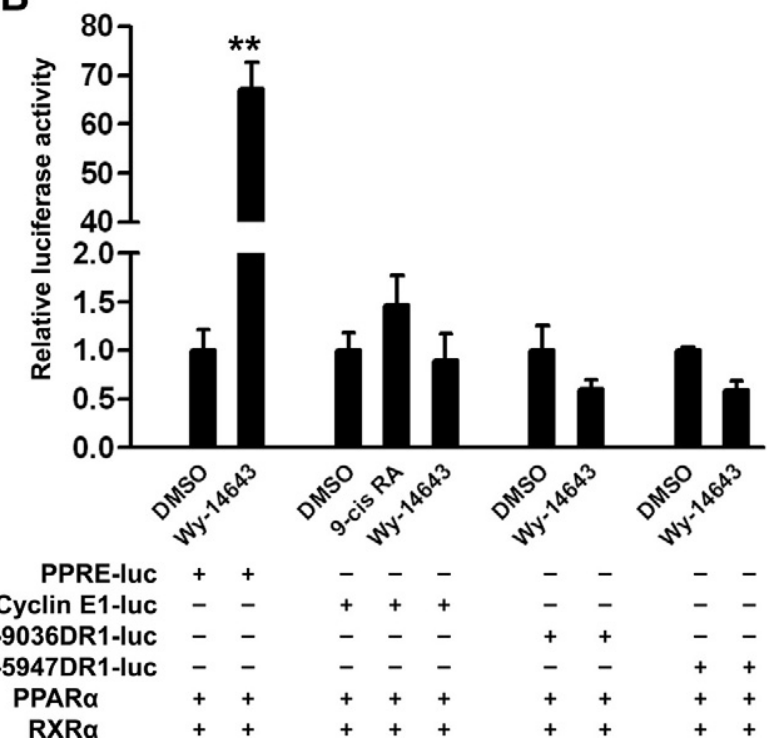

Figure 5. Identification of $\operatorname{RXR} \alpha$ homodimer as a positive and direct regulator of Cyclin E1 transcription. Huh7 cells were transiently transfected with the reporter construct and expression plasmids (A, RXR $\alpha$ homodimer; $\mathbf{B}$, RXR $\alpha$-PPAR $\alpha$ heterodimer) as shown. For each transfection, herpes simplex virus thymidine kinase promoter-driven Renilla reniformis luciferase was used as an internal control for normalization. Twenty-four hours after transfection, cells were subjected to respective ligand treatment at $10 \mu \mathrm{mol} / \mathrm{L}$ for 48 hours. Then cells were harvested and firefly and renilla luciferase activities were determined using a single tube TD20/20 luminometer. Results were expressed as mean $\pm \mathrm{SD}(n=3) .{ }^{*} P<0.05$ and ${ }^{* *} P<0.01$ versus dimethyl sulfoxide.

that liver regeneration is orchestrated by multiple signaling pathways. ${ }^{1}$

The current study expands the roles of nuclear receptors in liver regeneration. Several studies have documented the crucial roles of nuclear receptors that heterodimerize with $\mathrm{RXR} \alpha$ in liver regeneration ${ }^{2-4,7,29}$ (Table 2). Constitutive androstane receptor has been indicated to regulate early phase of hepatic regeneration in response to $\mathrm{PH}$. Absence of constitutive androstane receptor resulted in a modest decrease in liver growth at day 1 
combined with delayed DNA replication. ${ }^{2}$ FXR, a mediator of bile acid homeostasis, has been shown to be necessary for normal liver regeneration. FXR deficiency results in significant reduction in liver growth, which is accompanied by decreased DNA synthesis 3 days after $\mathrm{PH}$. However, at later stages, FXR-null mice had a rapid liver growth and no difference was found between wildtype and FXR-null mouse livers 7 days after $\mathrm{PH} .{ }^{2}$ The role of PXR in regulating $\mathrm{PH}$-induced liver regeneration has also been investigated. Using a percentage of original liver weight as a liver growth index, no defect in liver growth was detected in PXR-null mice at the early phase of liver regeneration. ${ }^{2}$ However, delayed liver regeneration was observed in PXR-null mice in our previous study associated with Stat3 inactivation, in which more studied time points were included and liver-to-body weight ratio was used to measure liver growth. ${ }^{7}$ The same genetic background of PXR-null mice was used in both studies. PPAR $\alpha$ is necessary for activation and membrane localization of Ras after $\mathrm{PH}$, which is involved in the activation of Cdks and initiation of G1/S phase transition. ${ }^{3}$ PPAR $\alpha$ null mice exhibited impaired liver regeneration within 48 hours after $\mathrm{PH}$, but regeneration caught up 72 hours post- $\mathrm{PH}^{3,4}$

The current paper demonstrates that hepatocyte $\mathrm{RXR} \alpha$ is essential for multiple signaling pathways that dictate normal progression of liver regeneration. The observed impairment of growth factor induction in our study might be specifically due to hepatocyte $\operatorname{RXR} \alpha$ deficiency, since such effects were not observed in mice lacking other nuclear receptors. However, since Bmal1 is a direct PPAR $\alpha$ target gene, ${ }^{20}$ hepatocyte $\mathrm{RXR} \alpha$ could regulate circadian clock gene expression through coupling with PPAR $\alpha$ or other signaling pathways and subsequently have an impact on cell cycle progression by targeting p21. In regenerating PPAR $\alpha$ knockout mouse livers, the expression of cyclin D1/Cdk4,Cdk2, and p27 was deregulated. ${ }^{3,4}$ Thus, cyclin D1/Cdk4 and Cdk2 gene expressions were commonly deregulated in regenerating hepatocyte PPAR $\alpha$ - and RXR $\alpha$-deficient mouse livers. Based on these findings, it is possible that deregulation of G1-S transition regulated by cyclin D1/Cdk4 and Cdk2 in $\operatorname{RXR} \alpha$-null mouse livers during liver regeneration is PPAR $\alpha$ / $\mathrm{RXR} \alpha$ dependent. Whether the deregulation of cyclin A2 and cyclin $\mathrm{B} 1 / \mathrm{Cdk} 1$ is $\mathrm{RXR} \alpha$ specific or $\operatorname{PPAR} \alpha / R X R \alpha$ dependent requires more investigation. In addition, retinoic acid can positively regulate cyclin E1 transcription via activation of $\operatorname{RXR} \alpha$ homodimer. As such, hepatocyte $\mathrm{RXR} \alpha$ has an impact on $\mathrm{G} 1, \mathrm{G} 2$, and $\mathrm{M}$ checkpoints and can be considered as a cell cycle modulator during liver regeneration. The identification of the roles of these nuclear receptors in liver regeneration provides considerable insights into the molecular mechanisms by which the liver is able to restore its original mass and function in response to liver mass loss.

Additionally, our data showed that the levels of hepatic PPAR $\alpha$ mRNA after PH fluctuated depending on when the mice were sacrificed with the levels elevated during the daytime but decreased at night. The pattern of expression is similar to that observed in normal liver. ${ }^{30}$ Profiling the time course of circadian clock gene expres- sion in both genotypes of mouse livers revealed that the rhythmic gene expression pattern was not $\mathrm{RXR} \alpha$-dependent. RXR $\alpha$-null mice displayed an expression pattern that was basically the same as their wild-type littermates for most of the hepatic clock genes except Cry2. This is reasonable since subsidiary circadian oscillators in many peripheral cell types including hepatocytes are synchronized by the master pacemaker in the suprachiasmatic nucleus of the brain in mammals. ${ }^{31}$ However, average expression levels and fluctuation of those clock-controlled genes after $\mathrm{PH}$ were changed due to the lack of $\operatorname{RXR} \alpha$, indicating that $\operatorname{RXR} \alpha$ might be involved in the mediation of circadian rhythm to some extent. The underlying molecular mechanisms need to be further investigated.

The involvement of $\mathrm{RXR} \alpha$ in liver regeneration has been examined by Imai's study, ${ }^{29}$ in which diminished hepatocyte lifespan and impaired hepatocyte regenerative capacity were reported. In the animal models used by Imai et al, ${ }^{29} R X R \alpha$ gene mutation leads to liver injury, increased hepatocyte proliferation, and impaired liver regeneration. Thus, increased hepatocyte proliferation during liver regeneration is likely due to a compensatory growth because of liver injury. However, the hepatocyte $\mathrm{RXR} \alpha$-deficient mouse model established by us does not have liver injury, which was monitored by ALT level and liver histology ${ }^{14,32}$; no liver injury was observed even when the mice were 24 months old (our unpublished finding). Our published data showed that hepatocyte $R X R \alpha$ deficiency results in changes in basal mRNA levels of many genes that are directly regulated by $\mathrm{RXR} \alpha$ and its heterodimeric partners, ${ }^{12,33}$ which confirmed the validity of the model established by us. Thus, the delayed liver regeneration observed in $\mathrm{RXR} \alpha$-null mice in our study is not relevant to liver injury. Furthermore, hepatocyte RXR $\alpha$ deficiency does not seem to have an effect on cell proliferation since the number of Ki-67-positive cells in the liver was not different between sham-operated wild-type and sham-operated hepatocyte RXR $\alpha$-null mice (data not shown). The reason for the discrepancy between our and Imai's findings is not clear. It could be due to a different region of the $R X R \alpha$ gene was deleted or a different genetic background of the mice was used in generating the RXR $\alpha$-null mice. Retinoic acids (9-cis-RA and all-trans RA) are known mitogens in rodent liver. ${ }^{34,35}$ Our data showed delayed liver regeneration due to hepatocyte $\mathrm{RXR} \alpha$ deficiency is consistent with the mitogenic effect of RAs in vivo.

One limitation of the present study is that some conclusions are based on mRNA analysis and the findings should be validated at the protein level. However, our overall finding indicated that hepatocyte proliferation was shifted 24 hours later due to hepatocyte deficiency. Deregulation of hepatocyte growth factor signaling pathway, impaired circadian clock-mediated cell cycle progression as well as irregular cell cycle gene expression in part account for such delay. Thus, hepatocyte $\mathrm{RXR} \alpha$ is required for multiple signaling pathways involved in hepatocyte proliferation during liver regeneration. 


\section{Acknowledgments}

We thank Dr. Ivan Damjanov for his critics and Ms. Barbara Brede for editing the manuscript.

\section{References}

1. Michalopoulos GK: Liver regeneration. J Cell Physiol 2007 213:286-300

2. Huang W, Ma K, Zhang J, Qatanani M, Cuvillier J, Liu J, Dong B, Huang X, Moore DD: Nuclear receptor-dependent bile acid signaling is required for normal liver regeneration. Science 2006, 312:233-236

3. Wheeler MD, Smutney OM, Check JF, Rusyn I, Schulte-Hermann R, Thurman RG: Impaired Ras membrane association and activation in PPARalpha knockout mice after partial hepatectomy. Am J Physiol Gastrointest Liver Physiol 2003, 284:G302-G312

4. Anderson SP, Yoon L, Richard EB, Dunn CS, Cattley RC, Corton JC: Delayed liver regeneration in peroxisome proliferator-activated receptor-alpha-null mice. Hepatology 2002, 36:544-554

5. Newberry EP, Kennedy SM, Xie Y, Luo J, Stanley SE, Semenkovich CF, Crooke RM, Graham MJ, Davidson NO: Altered hepatic triglyceride content after partial hepatectomy without impaired liver regeneration in multiple murine genetic models. Hepatology 2008 , 48:1097-1105

6. Rao MS, Peters JM, Gonzalez FJ, Reddy JK: Hepatic regeneration in peroxisome proliferator-activated receptor alpha-null mice after partial hepatectomy. Hepatol Res 2002, 22:52-57

7. Dai G, He L, Bu P, Wan YJ: Pregnane X receptor is essential for normal progression of liver regeneration. Hepatology 2008, 47: 1277-1287

8. Mangelsdorf DJ, Borgmeyer U, Heyman RA, Zhou JY, Ong ES, Oro AE, Kakizuka A, Evans RM: Characterization of three RXR genes that mediate the action of 9-cis retinoic acid. Genes Dev 1992, 6:329-344

9. Germain P, Chambon P, Eichele G, Evans RM, Lazar MA, Leid M, De Lera AR, Lotan R, Mangelsdorf DJ, Gronemeyer H: International Union of Pharmacology LXIII. Retinoid X receptors. Pharmacol Rev 2006, 58:760-772

10. Kastner P, Grondona JM, Mark M, Gansmuller A, LeMeur M, Decimo D, Vonesch JL, Dolle P, Chambon P: Genetic analysis of RXR alpha developmental function: convergence of RXR and RAR signaling pathways in heart and eye morphogenesis. Cell 1994, 78:987-1003

11. Sucov HM, Dyson E, Gumeringer CL, Price J, Chien KR, Evans RM: $\mathrm{RXR}$ alpha mutant mice establish a genetic basis for vitamin A signaling in heart morphogenesis. Genes Dev 1994, 8:1007-1018

12. Wan YJ, An D, Cai Y, Repa JJ, Hung-Po Chen T, Flores M, Postic C Magnuson MA, Chen J, Chien KR, French S, Mangelsdorf DJ, Sucov HM: Hepatocyte-specific mutation establishes retinoid $X$ receptor alpha as a heterodimeric integrator of multiple physiological processes in the liver. Mol Cell Biol 2000, 20:4436-4444

13. Greene AK, Puder M: Partial hepatectomy in the mouse: technique and perioperative management. J Invest Surg 2003, 16:99-102

14. Gyamfi MA, He L, French SW, Damjanov I, Wan YJ: Hepatocyte retinoid $X$ receptor alpha-dependent regulation of lipid homeostasis and inflammatory cytokine expression contributes to alcohol-induced liver injury. J Pharmacol Exp Ther 2008, 324:443-453

15. Pediaditakis P, Lopez-Talavera JC, Petersen B, Monga SP, Michalopoulos GK: The processing and utilization of hepatocyte growth factor/scatter factor following partial hepatectomy in the rat. Hepatology 2001, 34:688-693
16. Michalopoulos GK: HGF in liver regeneration and tumor promotion. Prog Clin Biol Res 1995, 391:179-185

17. Tomiya T, Ogata I, Fujiwara K: Transforming growth factor alpha levels in liver and blood correlate better than hepatocyte growth factor with hepatocyte proliferation during liver regeneration. Am J Pathol 1998, 153:955-961

18. Sturm J, Keese M, Zhang H, Bonninghoff R, Magdeburg R, Vajkoczy $P$, Dono R, Zeller R, Gretz N: Liver regeneration in FGF-2-deficient mice: vEGF acts as potential functional substitute for FGF-2. Liver Int 2004, 24:161-168

19. Murata S, Ohkohchi N, Matsuo R, Ikeda O, Myronovych A, Hoshi R: Platelets promote liver regeneration in early period after hepatectomy in mice. World J Surg 2007, 31:808-816

20. Grechez-Cassiau A, Rayet B, Guillaumond F, Teboul M, Delaunay F: The circadian clock component BMAL1 is a critical regulator of p21WAF1/CIP1 expression and hepatocyte proliferation. J Biol Chem 2008, 283:4535-4542

21. Matsuo T, Yamaguchi S, Mitsui S, Emi A, Shimoda F, Okamura H Control mechanism of the circadian clock for timing of cell division in vivo. Science 2003, 302:255-259

22. McNamara $P$, Seo SB, Rudic RD, Sehgal A, Chakravarti D, FitzGerald GA: Regulation of CLOCK and MOP4 by nuclear hormone receptors in the vasculature: a humoral mechanism to reset a peripheral clock. Cell 2001, 105:877-889

23. Canaple L, Rambaud J, Dkhissi-Benyahya O, Rayet B, Tan NS, Michalik L, Delaunay F, Wahli W, Laudet V: Reciprocal regulation of brain and muscle Arnt-like protein 1 and peroxisome proliferatoractivated receptor alpha defines a novel positive feedback loop in the rodent liver circadian clock. Mol Endocrinol 2006, 20:1715-1727

24. Desvergne B, Wahli W: Peroxisome proliferator-activated receptors: nuclear control of metabolism. Endocr Rev 1999, 20:649-688

25. Miller CW, Ntambi JM: Peroxisome proliferators induce mouse liver stearoyl-CoA desaturase 1 gene expression. Proc Natl Acad Sci USA 1996, 93:9443-9448

26. Yang X, Downes M, Yu RT, Bookout AL, He W, Straume M, Mangelsdorf DJ, Evans RM: Nuclear receptor expression links the circadian clock to metabolism. Cell 2006, 126:801-810

27. Schibler U: Circadian rhythms. Liver regeneration clocks on. Science 2003, 302:234-235

28. Gery S, Komatsu N, Baldjyan L, Yu A, Koo D, Koeffler HP: The circadian gene per1 plays an important role in cell growth and DNA damage control in human cancer cells. Mol Cell 2006, 22:375-382

29. Imai T, Jiang M, Kastner $P$, Chambon $P$, Metzger D: Selective ablation of retinoid $X$ receptor alpha in hepatocytes impairs their lifespan and regenerative capacity. Proc Natl Acad Sci USA 2001, 98:4581-4586

30. Yang X, Zhang YK, Esterly N, Klaassen CD, Wan YJ: Gender disparity of hepatic lipid homoeostasis regulated by the circadian clock. J Biochem 2009, 145:609-623

31. Schibler U, Sassone-Corsi P: A web of circadian pacemakers. Cell 2002, 111:919-922

32. Gyamfi MA, Wan YJ: Mechanisms of resistance of hepatocyte retinoid $X$ receptor a-null mice to $W Y-14,643$-induced hepatocyte proliferation and cholestasis. J Biol Chem 2009, 284:9321-9330

33. Wan YJ, Cai Y, Lungo W, Fu P, Locker J, French S, Sucov HM Peroxisome proliferator-activated receptor alpha-mediated pathways are altered in hepatocyte-specific retinoid $X$ receptor alpha-deficient mice. J Biol Chem 2000, 275:28285-28290

34. Ohmura T, Columbano GL, Columbano A, Katyal SL, Locker J, Shinozuka $\mathrm{H}$ : 9-cis retinoic acid is a direct hepatocyte mitogen in rats. Life Sci 1996, 58:PL211-P216

35. Ledda-Columbano GM, Pibiri M, Molotzu F, Cossu C, Sanna L, Simbula G, Perra A, Columbano A: Induction of hepatocyte proliferation by retinoic acid. Carcinogenesis 2004, 25:2061-2066 